\title{
Improving cross-sectoral climate change adaptation for coastal settlements: insights from South East Queensland, Australia
}

\author{
S. Serrao-Neumann $\cdot$ F. Crick $\cdot$ B. Harman • \\ M. Sano - O. Sahin • R. van Staden • \\ G. Schuch • S. Baum • D. Low Choy
}

Received: 25 June 2012/ Accepted: 8 March 2013/Published online: 22 March 2013

(c) The Author(s) 2013. This article is published with open access at Springerlink.com

\begin{abstract}
Climate change impacts affecting coastal areas, such as sea-level rise and storm surge events, are expected to have significant social, economic and environmental consequences worldwide. Ongoing population growth and development in highly urbanised coastal areas will exacerbate the predicted impacts on coastal settlements. Improving the adaptation potential of highly vulnerable coastal communities will require greater levels of planning and policy integration across sectors and scales. However, to date, there is little evidence in the literature which demonstrates how climate policy integration is being achieved. This paper contributes to this gap in knowledge by drawing on the example provided by the process of developing cross-sectoral climate change adaptation policies and programmes generated for three coastal settlement types as part of the South East Queensland Climate Adaptation Research Initiative (SEQCARI), a 3-year multisectoral study of climate change adaptation options for human settlements in South East Queensland, Australia. In doing so, we first investigate the benefits and challenges to cross-sectoral adaptation to address climate change broadly and in coastal areas. We then describe how cross-sectoral adaptation policies and programmes were generated and
\end{abstract}

Electronic supplementary material The online version of this article (doi:10.1007/s10113-013-0442-6) contains supplementary material, which is available to authorized users.

S. Serrao-Neumann $(\bowtie) \cdot$ F. Crick $\cdot$ M. Sano $\cdot$ O. Sahin .

R. van Staden · G. Schuch · S. Baum · D. Low Choy

Science, Environment, Engineering and Technology Group,

Griffith University, Nathan Campus,

Nathan, QLD 4111, Australia

e-mail: s.serrao-neumann@griffith.edu.au

B. Harman

Ecosystem Sciences, CSIRO, Canberra, ACT, Australia appraised involving the sectors of urban planning and management, coastal management, emergency management, human health and physical infrastructure as part of SEQCARI. The paper concludes by discussing key considerations that can inform the development and assessment of cross-sectoral climate change adaptation policies and programmes in highly urbanised coastal areas.

Keywords Adaptation - Climate policy · Policy integration · Adaptive management $\cdot$ Environmental policy

\section{Introduction}

A significant proportion of human settlements in coastal areas are considered to be vulnerable to climate-related impacts, including coastal and riverine flooding, sea-level rise and storm surge (Brooks et al. 2006; Solomon et al. 2007; Hunt and Watkiss 2011). In particular, highly urbanised low-lying coastal areas could be severely affected by climate change impacts considering that they now contain $10 \%$ of the world's population (McGranahan et al. 2007). Reflecting global coastal settlement patterns, about half of Australia's population lives within $7 \mathrm{~km}$ of the coast, with as many as $30 \%$ of the population living within $2 \mathrm{~km}$ of the coast (Chen and McAneney 2006). This trend is also observed in the South East Queensland (SEQ) region, which is likely to be severely affected by climate change impacts (Hennessy et al. 2007). In the last decades, SEQ has been subjected to sustained urban growth (Low Choy 2008), and the region is now experiencing one of the highest rates of population growth in Australia with its population expected to reach 4.4 million by 2031 (Australian Bureau of Statistics 2010). Ongoing coastal development and population growth are projected to exacerbate 
risks from sea-level rise and increases in the severity and frequency of storms and flooding events, prompting the Intergovernmental Panel on Climate Change to identify SEQ as one of six climate change vulnerability 'hot spots' in Australia (Hennessy et al. 2007).

Adapting to climate change in the coastal zone will be a complex process due to a combination of climate variability and uncertainty, the spatial and temporal dynamics of coastal systems and the multiplicity of stakeholders involved in managing the coastal zone (Nicholls et al. 2007). Specifically, the cross-scale interactions between different governance levels have implications for the way coastal zones are managed and therefore can adapt to climate change (McFadden 2010). In addition, climate adaptation policies also need to be better integrated across sectors to deal with important sectoral trade-offs inherent in climate adaptation policies (Tompkins et al. 2008) as well as reducing the risk of maladaptation (Barnett and O'neill 2010). Adapting to climate change in the coastal zone will therefore require both a cross-sectoral perspective and the involvement of multi-level governance systems.

The benefits associated with cross-sectoral approaches in addressing complex challenges, such as climate change adaptation, have been noted by Meadowcroft (2008). In particular, Meadowcroft suggests that cross-sectoral partnerships contribute to the development of innovative solutions and collective understanding and play an important role in sustainability governance. Despite the potential benefits, the integration of climate adaptation policy across sectors and scales remains a key challenge (Adger et al. 2005; Urwin and Jordan 2008). There have been limited studies focusing on the issue of coordination and harmonisation between policy making and implementation across sectors (Smith et al. 2009) as well as on the linkages between adaptation and cross-sectoral impacts (Hunt and Watkiss 2011). Climate policy integration, particularly involving adaptation, is a relatively new domain and is understood to be an additional interpretation beyond environmental policy integration related to sustainable development and sustainability (Jordan and Lenschow 2010).

This paper contributes to the emerging field of climate policy integration by identifying and discussing the process of developing cross-sectoral adaptation policies and programmes adopted in the human settlements component of the South East Queensland Climate Adaptation Research Initiative (SEQCARI). In doing so, we first identify the benefits and challenges, including the risk of maladaptation, involved in cross-sectoral integration in the context of climate adaptation at the local and regional scales. Focusing on the five sectors of urban planning and management, coastal management, emergency management, human health and physical infrastructure, the paper then describes the cross-sectoral research approach taken to develop and appraise adaptation options for three SEQ coastal settlements. This section focuses on the cross-sectoral process adopted by the research team to develop these adaptation options. The paper concludes by discussing the key insights observed in developing cross-sectoral climate adaptation for SEQ, along with a suggested approach to facilitate the implementation of these cross-sectoral options, and implications for other coastal areas elsewhere in Australia and globally.

\section{Challenges to cross-sectoral integration for climate change adaptation}

The impacts of climate change will not be confined to spatial or sectoral boundaries. As argued by Hunt and Watkiss (2011), climate impacts occur at a broad scale and even if some impacts might be mostly relevant to one specific sector they carry inherent interlinked cross-sectoral impacts. Calls for the need for cross-sectoral integration in decision making and policy formulation are not new and appear on a range of environment-related policy arenas (Stead and Meijers 2009). For example, Misselhorn et al. (2012) argue that integrated multi-disciplinary, cross-sectoral and cross-scale approaches to decision making are at the core of the concept of sustainability. The need for cross-sectoral linkages and initiatives has also been identified as being crucial when addressing food (Misselhorn et al. 2012) and water security (Bogardi et al. 2012), and global health linked to environmental change (Kovats and Butler 2012). While the importance and benefit of improved policy integration and coordination has attracted much scholarly attention, practical examples of the effectiveness of these approaches in dealing with complex planning and resource management outcomes are less evident (Jordan and Lenschow 2010). Perhaps this is a reflection of the time lag between policy development, implementation and on-ground outcomes. This is particularly evident in the environmental planning and policy arena where social and ecological benefits or costs associated with policy change may not be experienced till some years down the track. This issue is exacerbated in the climate change context, given the long-term nature of climate change impacts.

In the climate change context, policy integration is a relatively new field which stems from environmental policy integration related to sustainable development and sustainability (Jordan and Lenschow 2010). Drawing on the work of Underdal (1980) and Lafferty and Hovden (2003), Mickwitz et al. (2009:19) define climate policy integration as: 
the incorporation of the aims of climate change mitigation and adaptation into all stages of policymaking in other policy sectors (non-environmental as well as environmental); complemented by an attempt to aggregate expected consequences for climate change mitigation and adaptation into an overall evaluation of policy, and a commitment to minimise contradictions between climate policies and other policies.

While climate policy integration is a relatively new domain, there is a significant body of literature on the broader field of environmental policy integration which can inform how cross-sectoral integration for climate adaptation could be achieved (e.g. Underdal 1980; Nilsson and Persson 2003; Jordan and Lenschow 2010). Specifically, the benefits associated with key stakeholder interaction and involvement in the context of policy integration include improved rationality and effectiveness of policy making, reduced policy contradictions, reduced trade-offs and improved transparency. However, examples of effective environmental policy integration emerging from practice remain scarce (Stead and Meijers 2009; Nilsson and Persson 2012). Jordan and Lenschow (2010) argue that effective policy integration in the environmental sector has been hindered due to the soft character of instruments put in place which lack the power to establish a normative trend that makes integration a priority. Additionally, Ross and Dovers (2008) claim that environmental policy integration will only occur when gaps related to stronger leadership, cultural change and building capacity are overcome, leading to better uptake by administrative processes and structures. For Jacob et al. (2008), crosssectoral policy integration is also favoured by political commitment to implement it. This political domain has implications for setting priorities for policies as those can be ad hoc and bound to political interests and economical conditions often interrelated with public opinion and pressure from lobby groups (Nilsson 2005). Further, Daniell et al. (2011) also attribute the limited success in policy integration to perceived threats to traditional multilevel governance systems and problems associated with conceptual definitions, evaluation measures and appropriateness of policy integration.

The lack of effective policy integration is also evident in the climate change adaptation context (Urwin and Jordan 2008; Jordan and Lenschow 2010) despite the growing recognition that adaptation policy needs to be integrated across sectors and mainstreamed in the wider policy context (Daniell et al. 2011). Indeed, effective coordination across sectors is seen as a condition to avoid maladaptation (Stafford-Smith et al. 2012). In addition, Nilsson and Nilsson (2005) call for sectoral concerns to be addressed more strategically to advance climate policy. In this

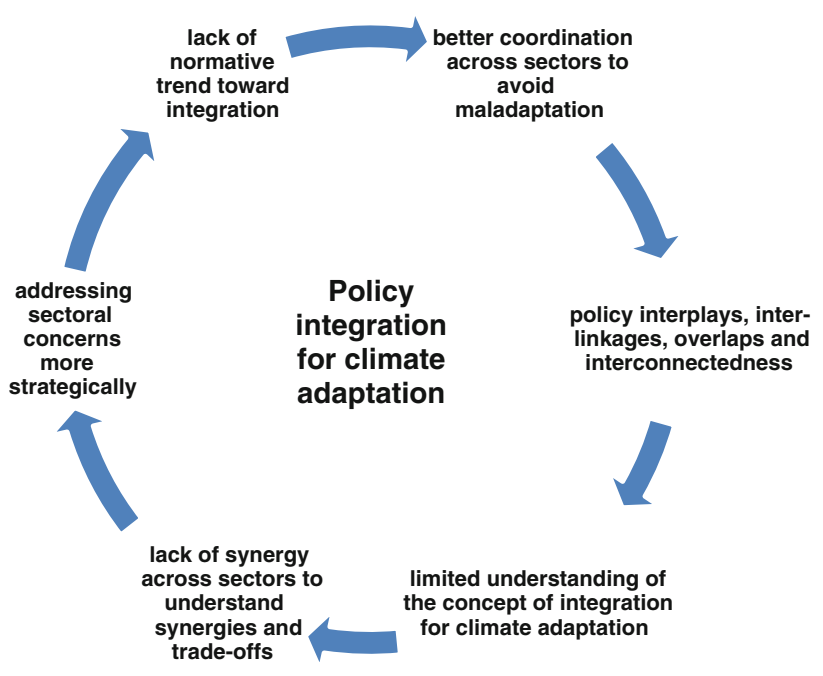

Fig. 1 Key challenges to policy integration for climate adaptation

context, cross-sectoral policy making must not only focus on the overarching goal or objective, but also consider both the spatial and temporal elements. Thus, sectoral needs must be considered when developing climate change adaptation policies to facilitate mainstreaming of adaptation in decision-making processes and better engagement across governments and departments (Smith et al. 2009).

However, policy integration for climate adaptation is challenging (see Fig. 1). The concept of integration itself is still unclear in the context of climate change adaptation and the barriers and opportunities to integration across sectors and scales need to be better understood (Burley et al. 2011). Attempts to integrate climate change within a broader policy or sector context need to take into consideration how different policies overlap and interact with each other (Young 2002; Oberthür and Gehring 2006) as well as the trade-offs between both policy formation and policy outcomes (Eakin et al. 2009). For example, Eakin et al. (2009) illustrate how different ways of adapting to climate change can favour efficient policy development over equitable policy outcomes or, on the other hand, favour equity outcomes at the expense of cost. Additionally, climate policy integration is impeded by the lack of capacity to identify and deal with synergies and contradictions between adaptation and other sectoral policies and by the reluctance of politicians to engage in climate change-related policies over other areas deemed to be of higher priority (Burley et al. 2011). Such policy interactions demand adequate coordination capacities to help clarify and identify cross-sectoral conflicts (Schout and Jordan 2008). Despite the consideration of potential conflicts and synergies, unforeseen impacts across sectors and scales may not materialise till years down the track. This reflects not only the inherent complexities between sectors 
and scales, but also the lag time between policy development, implementation and outcome. In addition, some policy objectives may rely on certain sequencing of policies across sectors to achieve the desired outcome. Where policies are implemented out of sequence, this may lead to poor policy performance, including the risk of maladaptation in the context of climate change.

In the next sections, we describe and discuss how crosssectoral integration was pursued by the human settlements component of SEQCARI in an attempt to overcome the challenges of policy conflict and maladaptation. It is important to note that the approach undertaken by the human settlements component is not the only one that could be suitable to facilitate the development of crosssectoral integration for climate change adaptation for coastal areas. We followed a learning-by-doing and doingby-learning process (Farrelly and Brown 2011) which involved extensive stakeholder engagement as we believe that the unforeseen impacts associated with cross-sectoral policy making may not be experienced until years well beyond the original policy conceptualisation and implementation phases. This suggests that ongoing monitoring, review and refinement of policies are required to reduce the risk of policy conflict and potential maladaptation.

\section{Human settlements research approach to cross-sectoral integration for climate adaptation}

From the outset, the SEQCARI project adopted a crosssectoral approach to climate change adaptation involving the sectors of urban planning and management, coastal management, human health, emergency management and physical infrastructure at the local government scale. The project also had a strong stakeholder collaborative component, which enabled stakeholders to provide feedback on the research throughout its duration. By being stakeholder focused, the human settlements component of SEQCARI aimed to bridge the science-policy interface, which has been identified as being critical to directly informing decision-making processes for climate change adaptation (Mastrandrea et al. 2010; Rosenzweig and Willbanks 2010; Schellnhuber 2010).

Stakeholders were involved in the research through a series of workshops and unstructured and semi-structured interviews (see Table 1). The workshops used a scenario planning approach (Schoemaker 1993) and included stakeholders representing all five sectors. The first series of workshops focused on the development of two possible future scenarios for SEQ, which were then used in the second series of workshops to test adaptation options. During workshops, stakeholders worked in both sectorspecific and cross-sectoral groups to ensure sector-specific and cross-sectoral issues were identified and discussed. Open plenary discussions and individual voting opportunities were also used. The interviews aimed to complement information obtained at the workshops and increase sectoral understanding of the policy process within government and non-government organisations, particularly in terms of climate change adaptation. A project reference group drawn from key stakeholders representing all sectors and various scales (local, regional and state) was also established at the start of the project to provide a forum for the researchers to discuss ideas and seek stakeholder opinion, advice and support as well as assist the project team to disseminate project outputs.

In brief, the research approach to cross-sectoral integration for climate adaptation involved four stages as shown in Fig. 2. First, the preliminary stage of investigation comprised a scoping study to investigate the key sectoral adaptation issues, identify the multi-scale roles and responsibilities of sectoral stakeholders and provide a regional-scale analysis of the policy and legislative framework for adaptation in SEQ (McDonald et al. 2010). It also comprised a regional spatial and sectoral vulnerability assessment to selected future climate-related impacts and a preliminary analysis of sectoral vulnerabilities at the regional scale (Low Choy et al. 2010).

Second, the case study development focused on key coastal settlements to enable the generation of more specific and tailored sectoral and cross-sectoral adaptation options. Selected case studies illustrate different regional coastal contexts (including biophysical and socio-economic), diverse challenges facing coastal zones based on their vulnerability and adaptive capacity, as well as specific sectoral vulnerabilities. Informed by the preliminary stage of investigation and discussions with key stakeholders, three settlement types were selected: canal estates, beachfront high-rise holiday destinations and coastal residential suburbs. Due to political sensitivities and in agreement with stakeholders, the case study locations were disguised by hypothetical locations and fictitious names, albeit constructed using real data (see Ts1 for a description of selected case studies).

Third, cross-sectoral adaptation options were developed based on an in-depth analysis of all sectoral policies and initiatives at state, regional and local levels related to climate change adaptation. This enabled the identification of existing adaptation or adaptation-relevant policies and initiatives and also provided a first indication of the gaps in adaptation policy in SEQ. A draft set of preliminary sectoral adaptation options for the selected case studies was then developed based on the analysis of existing initiatives, a review of the national and international literature and stakeholder input through workshops and interviews. Next, cross-sectoral workshops amongst the research team 
Table 1 Stakeholders involved in the human settlements component of SEQ CARI over the 3-year period

\begin{tabular}{|c|c|c|c|c|c|}
\hline \multirow[t]{2}{*}{ Stakeholder engagement process } & \multirow[t]{2}{*}{ Sector } & \multicolumn{4}{|c|}{ Number of participants per stakeholder groups and sectors } \\
\hline & & $\begin{array}{l}\text { Local } \\
\text { government }\end{array}$ & $\begin{array}{l}\text { State } \\
\text { government }\end{array}$ & $\begin{array}{l}\text { Industry } \\
\text { peak bodies }\end{array}$ & $\begin{array}{l}\text { Non-government } \\
\text { and community-based } \\
\text { organisations }\end{array}$ \\
\hline \multirow[t]{2}{*}{$\begin{array}{l}\text { A) } 2 \text { series of workshops ( } 3 \text { workshops } \\
\text { in series } 1 \text { and } 2 \text { workshops in series } 2 \text { ) }\end{array}$} & $\begin{array}{l}\text { Urban planning and } \\
\text { management }\end{array}$ & 29 & 5 & 4 & 6 \\
\hline & Emergency management & 15 & 12 & 1 & 2 \\
\hline B) 30 interviews & Human health & 16 & 8 & 2 & 4 \\
\hline \multirow[t]{2}{*}{ C) Project reference group workshops } & Physical infrastructure & 19 & 9 & - & - \\
\hline & Coastal management & 5 & 3 & - & 5 \\
\hline Number of participants & & 84 & 37 & 7 & 17 \\
\hline
\end{tabular}

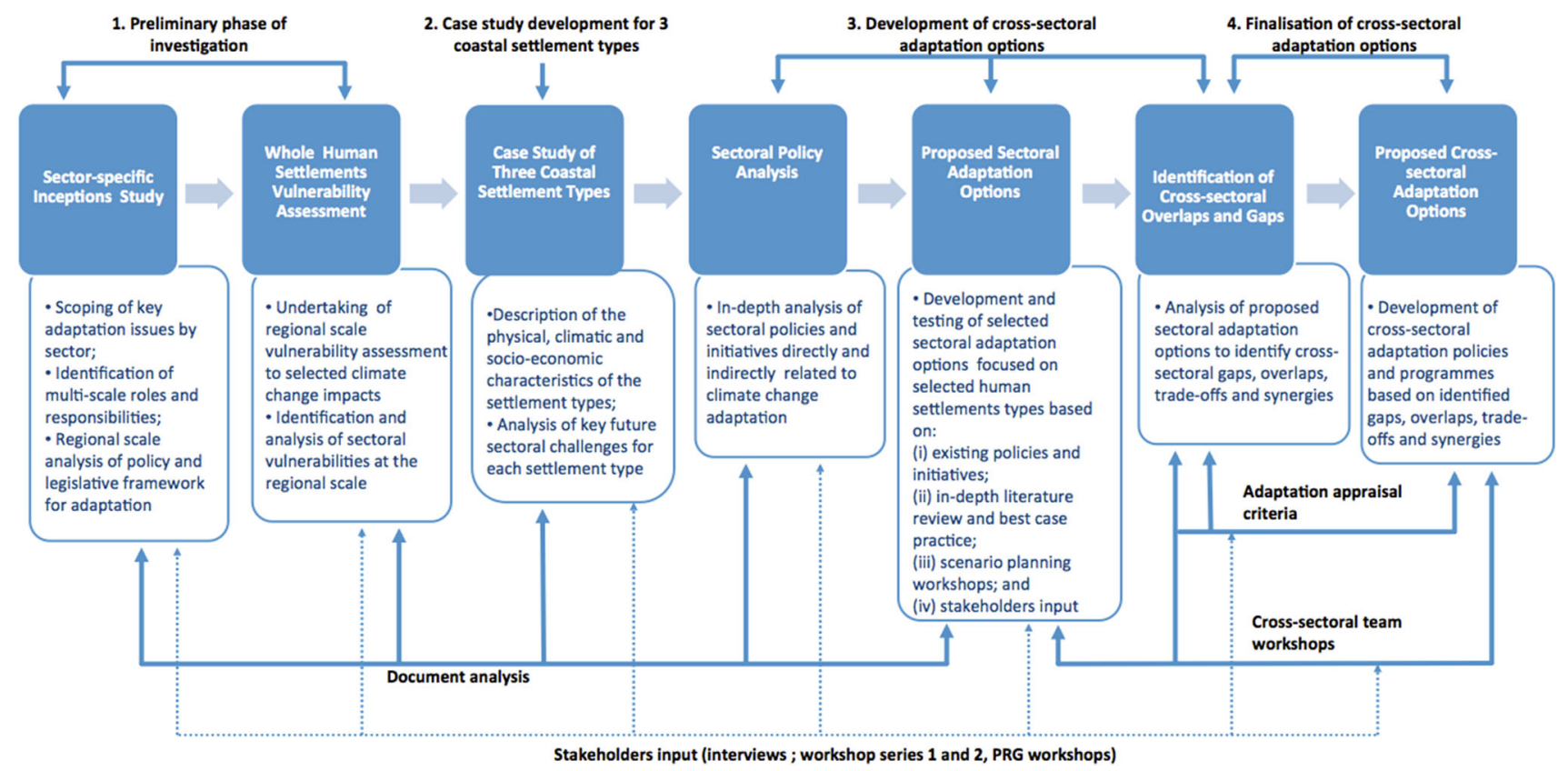

Fig. 2 Research approach to cross-sectoral integration for climate adaptation

members were held to identify the overlaps, gaps, synergies and cross-sectoral connections between the sectoral adaptation options and to develop cross-sectoral adaptation options.

Fourth, the final suite of adaptation options were first tested against eleven key adaptation appraisal criteria developed from a literature review and endorsed by the project reference group (see Ts2). A broader range of stakeholders also had the opportunity to assess selected adaptation options against these criteria in the second series of workshops. This exercise provided further feedback that was incorporated in the finalisation of cross-sectoral adaptation policies and programmes. This finalisation process involved the formulation of sector-specific adaptation frameworks for each sector, including an overarching goal followed by key policies and associated programmes and actions. These sector-specific adaptation frameworks were analysed through internal workshops involving the research team to identify and map cross-sectoral linkages. This process culminated in the generation of eight overarching adaptation themes based on the adaptation frameworks, key messages elicited from stakeholder feedback, document analysis and the literature: Preparing the Community; Support for Vulnerable Communities; Leadership, including Community Leadership; Proactive (Anticipatory) Initiatives; Managing the (Urban) Environment; Technological Development and Innovation; Risk Communication; and Training and Education (Low Choy et al. 2012). A suite of adaptation 
programmes across all five sectors was then proposed under each adaptation theme (see Ts3).

\section{Discussion}

There are many challenges to policy integration in the context of climate change adaptation (see Fig. 1), including the lack of a normative trend towards integration (Jordan and Lenschow 2010); the need to improve the understanding of the concept of integration itself for climate adaptation (Burley et al. 2011); a lack of synergy between sectors and understanding of trade-offs across sectors (Eakin et al. 2009; Burley et al. 2011); the need to improve the understanding of policy interplays, inter-linkages, overlaps and interconnectedness (Oberthür and Gehring 2006); addressing sectoral concerns more strategically (Nilsson and Nilsson 2005); and better coordination across sectors to avoid maladaptation (Barnett and O'neill 2010). The approach and methods selected from the outset of the project attempted to address these challenges to policy integration for climate change adaptation. However, it is important to note that while the research team developed cross-sectoral adaptation options for human settlements in SEQ in collaboration with stakeholders, subsequent on the ground uptake and implementation of these options did not fall within the remit of this project. Despite this being the ultimate long-term aim of SEQCARI and positive feedback from stakeholders that project outputs will be used to inform their work, the extent to which and time frame for the uptake to occur and for practical evidence of benefits associated with their implementation to become apparent is uncertain. Yet, drawing on the insights from the process of developing cross-sectoral adaptation options in a collaborative manner, we devise a suggested approach for the implementation of cross-sectoral and integrated climate change adaptation policies.

The development of cross-sectoral adaptation options in collaboration with stakeholders followed the conceptualisation of learning-by-doing and doing-by-learning proposed by Loorbach and Rotmans (2006:203) where the first 'concerns the development of theoretical knowledge from practice' and the second 'is the development of practical knowledge from theory'. From the human settlements research perspective, learning-by-doing was pursued by engaging stakeholders representing all sectors and various scales (local, regional and state) from the outset of and throughout the project. Through this level and breadth of stakeholder engagement, the research team was able to integrate the practice/corporate/agency knowledge across sectors when formulating and refining adaptation options. It also ensured the acknowledgement of existing policies promoting adaptation which were already adopted by the involved agencies. For example, one of the proposed crosssectoral adaptation options refers to the Integration of PostDisaster Recovery in Pre-Disaster Planning (see Ts3). In this case, stakeholders suggested that this adaptation option was already being considered to some extent in some of the local government disaster recovery plans as well as through the betterment notion included in the guidelines for disaster relief and recovery arrangements. However, they recognised that the idea of betterment was only recent and mainly restricted to infrastructure and particularly that much more attention needed to be given to improve community consultation and participation. They also stressed that this option might be difficult to communicate to the community because of its anticipatory and long-term nature and would therefore require significant community engagement and participation. These considerations elicited by stakeholders were then incorporated by the research team across a range of adaptation options, including the ones related to Managing the (Urban) Environment and Risk Communication.

In parallel, doing-by-learning was carried out by the research team by reframing adaptation options proposed in the literature to improve their capacity of being adopted and implemented in a pragmatic way based on stakeholders' feedback. An example that illustrates how this happened is the option concerning Planned Retreat which is widely accepted, albeit highly contested, as one of the adaptation alternatives to coastal areas in response to sealevel rise (McGranahan et al. 2007; Titus et al. 2009). Not surprisingly, this option displayed the greatest variation in assessment ratings amongst stakeholders perhaps due to mixed understanding about its nature, needs and effects. For example, stakeholders representing the development industry emphasised that if this option was introduced it should be at the discretion of informed property owners and occur as assets are retired, rather than at a set date. Additionally, they highlighted that incentives or compensation (possibly funded by governments) should be provided to affected landowners. Furthermore, stakeholders representing local governments highlighted that this option would require an advance by state government with local government support in solving the matter associated with 'injurious affection' in the current planning legislation. This matter was seen as a major stumbling block to the successful implementation of not only planned retreat but also other adaptation options because it opens up litigation potential against local governments. As a result, the research team ensured that options affected by these concerns were refined to incorporate actions that specifically focused on phasing the implementation of planned retreat while considering its social impact, potential funding alternatives and different implementation mechanisms as well as legislative barriers. 
Key insights to cross-sectoral integration for climate adaptation

In order to generate key insights that can inform crosssectoral integration for climate adaptation, we now investigate how the four main features of the human settlements research approach were conducive to overcome the identified challenges to policy integration outlined earlier (see Fig. 1). However, it is important to note that these are not stand-alone, but rather interdependent challenges and therefore will be discussed jointly.

First, a major methodological strength of the study relates to the distinct sectoral perspectives on the issues and challenges inherent to climate adaptation from both the multi-disciplinary research team and the breadth of stakeholders involved. This enabled the development of sectoral and cross-sectoral adaptation policies and programmes through an iterative and interactive process of collaboration between stakeholders and the multi-disciplinary research team which was conducive to achieving policy aggregation and consistency (cf. Underdal 1980). It was through this iterative and interactive process that proposed adaptation policies and programmes were legitimised by stakeholders and therefore representative of an overall perspective for climate adaptation rather than sector-specific. Additionally, policy consistency was pursued through the creation of opportunities through facilitated workshops for stakeholders from multiple sectors and distinct levels of governance to interact and discuss their perspectives and issues pertinent to their sectors for climate adaptation at the local and regional level. These opportunities did not happen without the expected tension in reconciling individual and collective interests that often emerges in collaboration exercises that involve a range of sectors and stakeholders (Thomson and Perry 2006). During workshops, cross-sectoral conflicts relating to adaptation options and potentially leading to maladaptation were identified, and areas for future research and policy development were noted. For example, there was wide interest among stakeholders for greater community involvement in disaster risk reduction. However, emergency management personnel present at workshops cautioned that when community involvement in disaster risk reduction does not occur within established disaster management operations and arrangements, this could affect disaster management operations. Consistency between autonomous community-level actions during disaster response and recovery, and established disaster management operations was then noted as an area in need of greater attention by researchers and all stakeholders present at workshops. Using an adaptive management approach, efforts to address these identified areas of conflict across sectors may be monitored and altered over time.
Second, tension in reconciling individual and collective interests was managed by carefully selecting, involving and mixing stakeholders from a variety of sectors and governance levels to reduce the risk of over-representation and dominance of individual stakeholder groups. Moreover, the adoption of a hypothetical case study approach (see below) and use of scenario planning to guide the conduct of workshops allowed discussions to transcend current vested interests towards a more strategic and complementary position to support climate change adaptation. For example, in the second series of workshops, stakeholders were grouped in cross-sectoral teams to test adaptation options against plausible future scenarios and adaptation appraisal criteria. Group discussions were facilitated by research team members to ensure considerations from all sectors were heard, particularly to clarify roles and responsibilities different sectors, stakeholders and organisations have in their day-to-day operations that can create barriers and/or opportunities for climate change adaptation. Additionally, stakeholders had the opportunity to individually appraise proposed adaptation options anonymously and therefore express their own interests without being confronted by other participants. However, consideration was given to the limitations involved in stakeholder engagement which, if not considered, can raise false expectations in terms of the breadth of achieved stakeholder representation and/or inclusion (Few et al. 2007). Hence, the research team acknowledges that the inclusion of citizens and political leaders in the described process adds an additional layer of complexity that deserves further investigation.

Third, the adoption of a case study approach, which focused on specific coastal settlement types, assisted in the identification and investigation of sector-specific issues and policy needs for climate adaptation. It also provided scope for the discussion of linkages across sectors to avoid tradeoffs between sectors, define strategic issues as well as enhance the 'effectiveness' (cf. Adger et al. 2005) of proposed adaptation policies and programmes. For example, one of the settlement types-canal estates-is surrounded by waterways which demand a close interlink between the sectors of urban planning and management, physical infrastructure and emergency management. Increasing population density in those areas, for instance, could add additional pressures on ageing stormwater systems and lead to higher flood levels which, in turn, would have a direct impact on evacuation routes. By focusing on specific geographical localities exemplified by settlement types, the project was aligned with a growing body of literature that indicates that climate change adaptation is context specific and the impacts need to be addressed at the local scale (Measham et al. 2011). Nevertheless, links between localand regional-scale policies were not ignored as regional policies also influence how those local areas are managed. 
This is an important aspect relevant to policy integration as it can lead to inconsistencies across sectors and levels of governance (Underdal 1980; Portman 2011).

It is important to note that the selection of case studies was confronted with typical political, institutional, social and legal barriers given the limited focus on climate change adaptation in Australia to date, compounded by the absence of strong leadership on climate change adaptation from all levels of government nationally (Preston et al. 2011). Stakeholders expressed concerns relating to the political ramifications of any research outputs that were based on uncertain science and/or timelines beyond time frames that local governments have solid policy for, and that related to the context of broader, politically charged climate change debates. These potential 'project stopping' barriers were overcome through negotiated agreements with participating local authorities to undertake the research using a hypothetical case study approach. While such an approach could have potentially constrained independent research and analysis of individual specific cases, it provided a platform for more open discussion and debate among stakeholders by focusing on what should be done rather than what could be done in the current political climate. The project reference group also provided valuable input regarding identifying and addressing potential challenges and conflicts inherent in, and particular to, cross-sectoral policy development in the region.

Fourth, to ensure policies developed across the five sectors were consistent (cf. Underdal 1980), all adaptation policies and programmes generated were appraised against eleven criteria (see Ts2). This process informed the final selection and prioritisation of adaptation policies and programmes and reduced the risk of sectoral trade-offs, thereby also minimising the risk of maladaptation. The appraisal criteria were derived from a review of the literature on 'best practice' adaptation, and a combination of expert opinion from the research team and key stakeholders. By allowing input from key stakeholders and practitioners in the refinement of the appraisal criteria and development of adaptation policies and programmes, greater levels of transparency, accountability and trust were enabled. The high level of stakeholder involvement in the process promoted greater accountability and in turn ownership of outcome and potential adoption of adaptation policies and programmes.

In summary, there are three key insights that emanate from the experience provided by the human settlements approach which could inform climate change adaptation in other coastal areas. First, for climate adaptation policies to be integrated, a range of sectors needed to be involved in all stages of the integration process, that is, from the identification of key issues and challenges and throughout the formulation and assessment stages. This process needs to be interactive and iterative and should include a range of stakeholders representing different sectors and governance levels. Nevertheless, the human settlements cross-sectoral approach demanded a significant amount of effort and conciliation from participants as well as negotiations throughout the project within the research team and between the research team and stakeholders. The use of hypothetical case studies and scenario planning contributed to minimising interest disparities amongst stakeholders as well as overcoming project stopping barriers of institutional, political, legal and social nature. Second, the adopted case study approach allowed the development of adaptation policies and programmes addressing specificities of identified locations as well as the identification of synergies and trade-offs across sectors beyond the local scale. This approach also assisted in the mapping of interplays, inter-linkages, overlaps and interconnectedness across and between existing policies by clearly identifying cascading effects or implications one sectoral policy might have on other sectors. This was important to guide the development of proposed sector-specific and cross-sectoral adaptation policies and programmes, particularly from a more strategic and long-term perspective. Third, the development of appraisal criteria to assess adaptation policies and programmes further contributed to minimising policy trade-offs across sectors, although some trade-offs may not be known until policies are fully implemented and feedback from social and ecological systems are realised. Additionally, while the criteria may not totally prevent maladaptation from occurring due to other external pressures, such as political interests, it comprised a useful tool to identify adaptation options that require caution in their conceptualisation and implementation. On that note, it is also important to stress the role that adaptive management approaches play in ensuring cross-sectoral integration and adaptation. In addition, iteration across sectors is essential to overcome previously identified challenges to policy integration.

\section{Moving forward towards cross-sectoral adaptation}

Overcoming the principal challenges for achieving successful cross-sectoral adaptation to climate change will require a concerted, continuous and integrated (joined-up) effort. To this end, the consolidation of various groupings of policies and programmes into adaptation themes can provide an insight into the implementation end of the adaptation process (see Ts3). Additionally, the proposed adaptation policies and programmes were framed in an adaptive management context (cf. Tompkins and Adger 2004) and derived through the consideration of a cyclic planning process that incorporates an adaptive management framework. This facilitates the ability to continuously 
review these options in the light of new and revised science and learnings. This cyclic approach (cf. Willows and Connell 2003) has meant that implementation issues have had to be considered and aspects of monitoring and evaluation addressed in terms of the implementation of the adaptation options.

Based on these insights, we argue that one possible pathway to improve cross-sectoral integration for climate change adaptation is by following consolidated adaptation themes which can be approached through five adaptation implementation phases, namely foundation phase, substantiation phase, mainstreaming phase, review phase and consolidation phase. The assignment of these eight adaptation themes into a proposed sequencing arrangement of five implementation phases provides further insight into the requirements for implementing potential strategies to address cross-sectoral adaptation of human settlements. The proposed arrangement and sequencing of the eight adaptation themes across the various adaptation implementation phases are illustrated in Fig. 3. Strong evidence has emerged, especially from stakeholder engagement supported by the literature (Measham et al. 2011; Preston et al. 2011), that well-informed leadership that is confident in the adaptation process is essential. For this reason, this suite of leadership programmes is foundational to the successful implementation of all other adaptation options. However, a concerted effort will have to be made to achieve these ends, and it will require a continual undertaking to address the churn that characterises the nature of leadership at institutional and community levels.

A further clear message from the stakeholder engagement process was the need to ensure continuity of effort, as it was repeatedly noted that there had to be continuity of support, capacity building and adaptation programmes to guarantee success, particularly in a cost-effective manner over longer time frames. In some cases, this could be achieved through sporadic initiatives ramped up as required, but in other instances, it is clear that this effort must be ongoing. A casein-point is the adaptation themes related to capacity building through Training and Education, Managing the (Urban) Environment and Risk Communication. These adaptation themes, along with leadership, underlie the foundation and
Fig. 3 Phases of adaptation implementation

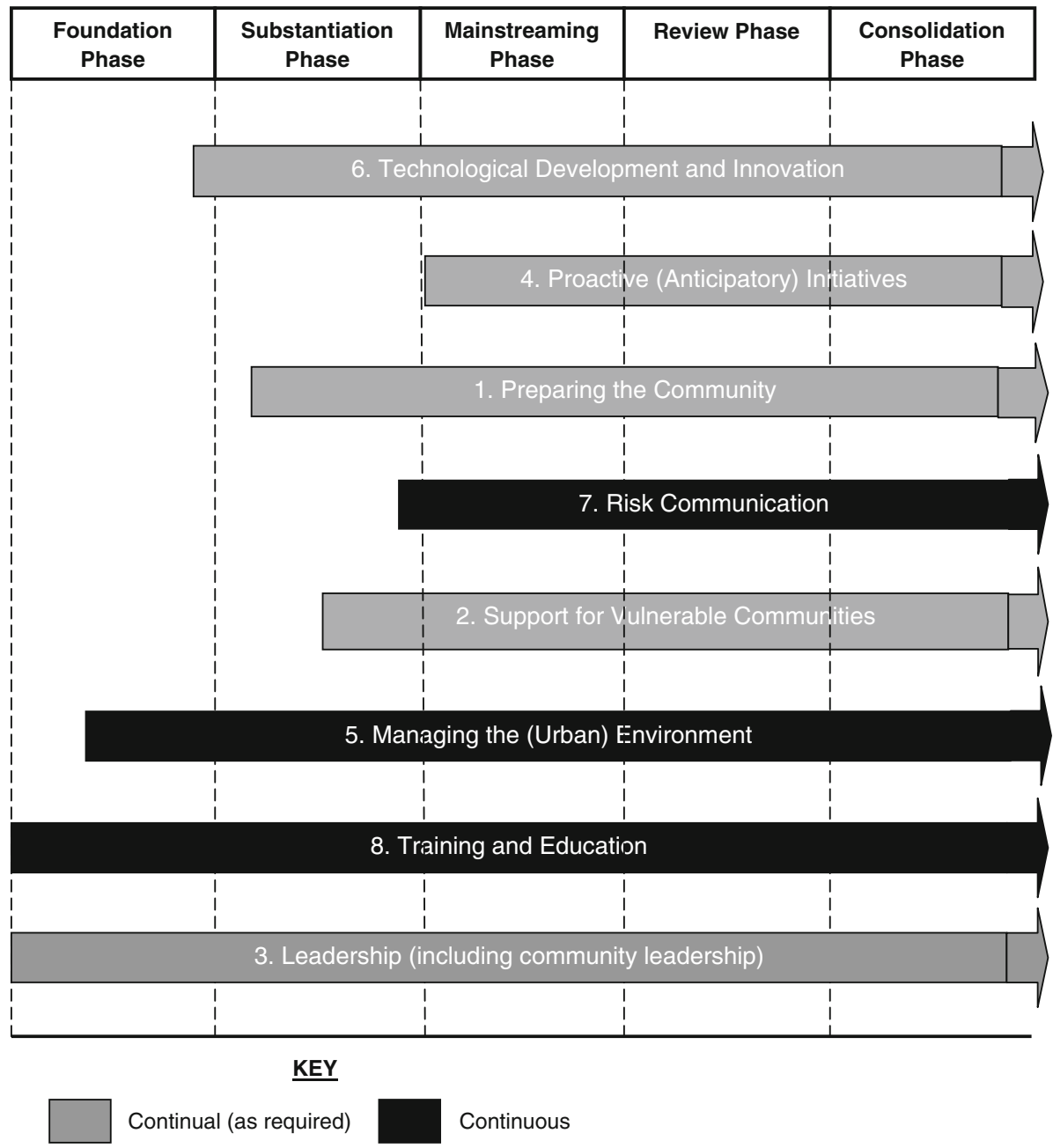


substantiation phases. By the mainstreaming phase, the relevant programmes of all the adaptation themes should have been initiated and should be operating in a coordinated and joined-up manner. The review phase highlights the overarching approach that imbeds an adaptive management framework into the implementation process. Hence, there are a number of adaptive management cycles operating throughout the human settlements adaptation options. In addition to the review phase, an extensive range of additional adaptive management measures have been built into each programme and associated actions. Subsequently, and subject to feedback and learnings from the review phase, the desired programmes in their modified (or unmodified) form proceed through to the consolidation phase. However, it is important to reemphasise an earlier acknowledgement that each location and circumstance is different (sometimes unique). Hence, not all individual programmes and actions need to or will be included in all adaptation themes for specific cases of implementation. That said, it is also important to note that some programmes can have a crosssectoral application. Examples of cross-sectoral adaptation options that apply to all human settlements sectors include risk communication, information sharing, capacity building and training, public awareness and education, leadership development, post-disaster into pre-disaster planning, planned retreat, physical and social infrastructure management, and adaptive management.

There is no 'one-size-fits-all' approach; however, it is clear that this pathway will require improved collaboration across sectors and ongoing engagement of stakeholders from a range of sectors and levels of governance.

\section{Conclusion}

Globally, highly urbanised coastal areas comprise contested landscapes characterised by a plurality of social, economic and environmental values and interests. Managing the predicted impacts of climate change in dynamic coastal environments requires the cooperation of key sectors and scales of governance. It also requires a shift from the dominant paradigm of sectoral policies and decision making towards an integrated approach involving crosssectoral policies and practices which are considerate of both spatial and temporal dimensions. This paper highlights the importance of cross-sectoral policy integration to manage climate change impacts in coastal areas by articulating the process used by the human settlements research team to develop policies, programmes and actions at the local and regional scale. This study has demonstrated the importance of cross-sectoral integration and the need to involve a wide range of stakeholders when formulating adaptation policies. It is also important to note that there is no 'one-model-fits-all' when it comes to adapting to climate change in coastal areas, and future studies are needed to further improve the understanding of the concept of integration itself for climate adaptation. Although the cross-sectoral approach adopted in this study attempted to account for policy conflicts and trade-offs between sectors at the conceptual level, it is important to note that unforeseen impacts may not be realised until years ahead. This is indicative of the need to maintain close monitoring, evaluation and refinement of policies and practices over long time frames as well as the need for adaptive management cycles to be pursued in climate adaptation.

While this study provided some insights in terms of how cross-sectoral integration could be achieved when developing adaptation options, there are additional challenges to policy integration that require further consideration in future studies. These include the need to consider climate policy and objectives and goals by external sectors not involved in cross-sectoral integration exercises, and the lack of a normative trend towards policy integration within the climate adaptation context. Last, we are just starting to improve our understanding of the concept of integration for climate adaptation which will be shaped and revisited as we progress towards actual adaptation implementation.

Acknowledgments This paper is part of the South East Queensland Climate Adaptation Research Initiative, a partnership between the Queensland and Australian Governments, the CSIRO Climate Adaptation National Research Flagship, Griffith University, The University of the Sunshine Coast and The University of Queensland. The Initiative aims to provide research knowledge to enable the region to adapt and prepare for the impacts of climate change.

Open Access This article is distributed under the terms of the Creative Commons Attribution License which permits any use, distribution, and reproduction in any medium, provided the original author(s) and the source are credited.

\section{References}

Adger N, Arnell N, Tompkins E (2005) Successful adaptation to climate change across scales. Glob Environ Change Part A 15:77-86

Australian Bureau of Statistics (2010) 3235.0_population by age and sex, Regions of Australia, Queensland. http://www.abs.gov.au/ ausstats/abs@.nsf/Products/3235.0 2010 Main+Features Queensland?OpenDocument, Accessed 9/3/12

Barnett J, O'neill S (2010) Maladaptation. Glob Environ Change 20:211-213

Bogardi J, Dudgeon D, Lawford R, Flinkerbusch E, Meyn A, Pahl-Wostl C, Vielhauer K, Vörösmarty C (2012) Water security for a planet under pressure: interconnected challenges of a changing world call for sustainable solutions. Curr Opin Environ Sustain 4:35-43

Brooks N, Hall J, Nicholls R (2006) Sea-level rise: coastal impacts and responses. The German Advisory Council on Global Change (WBGU), Berlin 
Burley J, McAllister R, Collins K, Lovelock C (2011) Integration, synthesis and climate change adaptation: a narrative based on coastal wetlands at the regional scale. Reg Environ Change. doi: 10.1007/s10113-011-0271-4

Chen K, McAneney J (2006) High-resolution estimates of Australia's coastal population. Geophys Res Lett 33:1-4

Daniell K, Máñez Costa M, Ferrand N, Kingsborough A, Coad P, Ribarova I (2011) Aiding multi-level decision-making processes for climate change mitigation and adaptation. Reg Environ Change 11:243-258

Eakin H, Tompkins E, Nelson R, Anderies J (2009) Hidden costs and disparate uncertainties: trade-offs in approaches to climate policy. In: Adger N, Lorenzoni I, O’brien K (eds) Adapting to climate change: thresholds, values, governance. Cambridge University Press, Cambridge, pp 212-226

Farrelly M, Brown R (2011) Rethinking urban water management: experimentation as a way forward? Glob Environ Change 21:721-732

Few R, Brown K, Tompkins E (2007) Public participation and climate change adaptation: avoiding the illusion of inclusion. Clim Policy 7:46-59

Hennessy K, Fitzharris B, Bates B, Harvey N, Howden M, Hughes L, Salinger J, Warrick R (2007) Australia and New Zealand. In: Parry M, Canziani O, Palutikof J, Van Der Linden P, Hanson C (eds) Climate change 2007: impacts, adaptation and vulnerability. Contribution of working group II to the fourth assessment report of the intergovernmental panel on climate change. Cambridge University Press, Cambridge, pp 507-540

Hunt A, Watkiss P (2011) Climate change impacts and adaptation in cities: a review of the literature. Clim Change 104:13-49

Jacob K, Volkery A, Lenschow A (2008) Instruments for environmental policy integration in 30 OECD countries. In: Jordan A, Lenschow A (eds) Innovation in environmental policy? integrating the environment for sustainability. Edward Elgar, Cheltenham

Jordan A, Lenschow A (2010) Environmental policy integration: a state of the art review. Environ Policy Gov 20:147-158

Kovats R, Butler C (2012) Global health and environmental change: linking research and policy. Curr Opin Environ Sustain 4:44-50

Lafferty W, Hovden E (2003) Environmental policy integration: towards an analytical framework. Environ Politics 12:1-22

Loorbach D, Rotmans J (2006) Managing transitions for sustainable development. In: Olshoorn X, Wieczorek A (eds) Understanding industrial transformation, views from different disciplines. Springer, Dordrecht, pp 187-206

Low Choy D (2008) The SEQ regional landscape framework: is practice ahead of theory? Urban Policy Res 26:111-124

Low Choy D, Baum S, Serrao-Neumann S, Crick F, Sanò M, Harman B (2010) Climate change vulnerability in South East Queensland: a spatial and sectoral assessment, a report for the South East Queensland climate adaptation research initiative. Griffith University

Low Choy D, Serrao-Neumann S, Crick F, Schuch G, Sanò M, van Staden R, Sahin O, Harman B, Baum S (2012) Adaptation options for human settlements in South East Queensland-main report, a report for the South East Queensland climate adaptation research initiative. Griffith University

Mastrandrea M, Heller N, Root T, Schneider S (2010) Bridging the gap: linking climate-impacts research with adaptation planning and management. Clim Change 100:87-101

McDonald J, Baum S, Crick F, Czarnecki J, Field G, Low Choy D, Mustelin J, Sanò M, Serrao-Neumann S (2010) Climate change adaptation in South East Queensland human settlements: issues and context, a report for the South East Queensland climate adaptation research initiative. Griffith University
McFadden L (2010) Exploring systems interactions for building resilience within coastal environments and communities. Environ Hazards 9:1-18

McGranahan G, Balk D, Anderson B (2007) The rising tide: assessing the risks of climate change and human settlements in low elevation coastal zones. Environ Urban 19:17-37

Meadowcroft J (2008) Democracy and accountability: the challenge for cross-sectoral partnerships. In: Glasbergen P, Biermann F, Mol A (eds) Partnerships, governance and sustainable development: reflections and theory and practice. Edward Elgar, Northampton, pp 194-213

Measham T, Preston B, Smith T, Brooke C, Gorddard R, Withycombe G, Morrison C (2011) Adapting to climate change through local municipal planning: barriers and challenges. Mitigation and adaptation strategies for global change http://dx.doi.org/10. 1007/s11027-011-9301-2

Mickwitz P, Aix F, Beck S, Carss D, Ferrand N, Görg C, Jensen A, Kivimaa P, Kuhlicke C, Kuindersma W, Máñez M, Melanen M, Monni S, Pedersen A, Reinert H, van Bommel S (2009) Climate policy integration, coherence and governance. PEER Report 2, PEER, Helsinki

Misselhorn A, Aggarwal P, Ericksen P, Gregory P, Horn-Phathanothai L, Ingram J, Wiebe K (2012) A vision for attaining food security. Curr Opin Environ Sustain 4:7-17

Nicholls R, Wong P, Burkett V, Codignotto J, Hay J, McLean R, Ragoonaden S, Woodroffe C (2007) Coastal systems and lowlying areas. Climate change 2007: impacts, adaptation and vulnerability. Contribution of working group II to the fourth assessment report of the intergovernmental panel on climate change, pp. 315-356

Nilsson M (2005) Learning, frames, and environmental policy integration: the case of Swedish energy policy. Environ Plan C Govern Policy 23:207-226

Nilsson M, Nilsson L (2005) Towards climate policy integration in the EU: evolving dilemmas and opportunities. Clim Policy 5:363-376

Nilsson M, Persson Ã (2003) Framework for analysing environmental policy integration. J Environ Plan Policy Manage 5:333-354

Nilsson M, Persson Ã (2012) Can Earth system interactions be governed? Governance functions for linking climate change mitigation with land use, freshwater and biodiversity protection. Ecol Econ 75:61-71

Oberthür S, Gehring T (2006) Institutional interaction in global environmental governance. MIT Press, Cambridge

Portman M (2011) Marine spatial planning: achieving and evaluating integration. J Marine Sci 68:2191-2200

Preston B, Danese C, Yuen E (2011) Embedding climate change risk assessment within a governance context. Linking research to practice: knowledge, measurement and policymaking, 2011 Colorado conference on earth system governance: crossing boundaries and building bridges, May 2011, pp. 17-20

Rosenzweig C, Willbanks T (2010) The state of climate change vulnerability, impacts, and adaptation research: strengthening knowledge base and community. Clim Change 100:103-106

Ross A, Dovers S (2008) Making the harder yards: environmental policy integration in Australia. Aust J Public Adm 67:245-260

Schellnhuber H (2010) Tragic triumph. Clim Change 100:229-238

Schoemaker P (1993) Multiple scenario development: its conceptual and behavioral foundation. Strateg Manag J 12:193-213

Schout A, Jordan A (2008) Administrative instruments. In: Jordan E, Lenschow A (eds) Innovation in environmental policy?: integrating the environment for sustainability. Edward Elgar Publishing, Northampton, pp 49-69

Smith J, Vogel J, Cromwell J III (2009) An architecture for government action on adaptation to climate change. An editorial comment. Clim Change 95:53-61 
Solomon S, Qin D, Manning M, Chen Z, Marquis M, Averyt K, Tignor M, Miller H (2007) Summary for policymakers. Climate change 2007: the physical science basis. Contribution of working group I to the fourth assessment report of the intergovernmental panel on climate change

Stafford-Smith M, Gaffney O, Brito L, Ostrom E, Seitzinger S (2012) Interconnected risks and solutions for a planet under pressureoverview and introduction. Curr Opin Environ Sustain 4:3-6

Stead D, Meijers E (2009) Spatial planning and policy integration: concepts, facilitators and inhibitors. Plan Theory Pract 10: $317-332$

Thomson A, Perry J (2006) Collaboration processes: inside the black box. Public Adm Review 66:20-32

Titus J, Hudgens D, Trescott D, Craghan M, Nuckols W, Hershner C, Kassakian J, Linn C, Merritt P, McCue T, O’Connell J, Tanski J, Wang J (2009) State and local governments plan for development of most land vulnerable to rising sea level along the US Atlantic coast. Environ Res Lett 4:1-7
Tompkins E, Adger N (2004) Does adaptive management of natural resources enhance resilience to climate change? Ecol Soc 9:10

Tompkins E, Few R, Brown K (2008) Scenario-based stakeholder engagement: incorporating stakeholders preferences into coastal planning for climate change. J Environ Manage 88:1580-1592

Underdal A (1980) Integrated marine policy: What? Why? How? Marine Policy 4:159-169

Urwin K, Jordan A (2008) Does public policy support or undermine climate change adaptation? Exploring policy interplay across different scales of governance. Glob Environ Change 18: $180-191$

Willows R, Connell R (eds) (2003) Climate adaptation: risk, uncertainty and decision-making, UKCIP Technical Report. UKCIP, Oxford

Young O (2002) The institutional dimensions of environmental change: fit, interplay, scale. MIT Press, Cambridge 